\title{
ENGAGING COMMUNITIES IN REBUILDING POST-TYPHOON YOLANDA IN THE PHILIPPINES
}

Communities are slowly being rebuilt after Super Typhoon Yolanda (also known as Typhoon Haiyan) struck the Visayas Islands in the Philippines in November 2013. The vulnerable, most affected communities face ongoing challenges to re-establish livelihoods, safe housing, access to water and electricity, and to rebuild roads and drainage. Aid agencies, active on the ground in the immediate aftermath, have since left the region, leaving national and local government, policymakers and affected communities to respond to the long-term legacy.

Researchers at the University of Nottingham, UK and Ningbo, China in partnership with the University of the Philippines, Diliman have worked closely with local communities to articulate the lessons from Typhoon Yolanda. Their recommendations for national and local policymakers and government officials, civil society groups, and foreign aid agencies involved in future disaster work show signs of adoption as agencies take on board the importance of engaging affected communities in recovery and rehabilitation plans.

\section{THE CHALLENGE}

Typhoon Yolanda brought death and devastation, leaving over four million people displaced and over a million homes destroyed. Progress to rebuild and resettle homeless inhabitants has been made since a new phase of recovery commenced from 2015. Large infrastructure projects have been undertaken, or are ongoing; and an extensive number of public and private relocation shelters have been erected. Many people who lost their homes have new ones. Local buildings - barangay halls (the barangay is the smallest political unit with elected officials), multipurpose buildings,

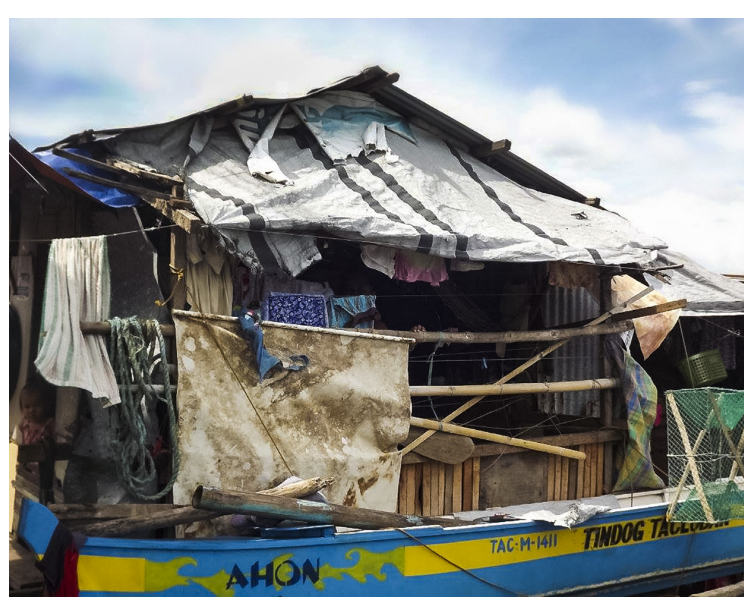

Cover photo: Communities attempt to rebuild their lives amidst the debris left behind by Typhoon Yolanda. Credit: Dr Pauline Eadie, University of Nottingham 2018. and schools - are complete; community areas, such as sports pitches, have been restored or re-established; and roads resurfaced.

However, for many vulnerable communities affected by the typhoon, recovery was so long in coming that people have rebuilt them in dangerous coastal areas Some communities are resistant to being resettled away from danger zones as resettlement plans failed to engage them in the design or implementation, whilst newly constructed homes remain unoccupied because water and electricity are not yet in place. Some may be ready to promote tourism in Tacloban, presenting successful recovery and 'resilient' populations, but life remains difficult for many who have yet to be safely resettled, to establish sustainable livelihoods, or gain access to basic services and sanitation.

\section{THE RESEARCH}

This research, which was funded by the ESRC-DFID Joint Fund for Alleviation Research in 2015-18, set out to explore the challenges that different stakeholders faced during the recovery and rebuilding process in the wake of Typhoon Yolanda, and to create solutions for future strategies responding to disaster.

The researchers carried out 200 interviews with nongovernmental organisations (NGOs) and government personnel; held 50 focus groups with local people to discuss their concerns about the rebuilding process; and conducted a documents review. The researchers also 
undertook three household surveys from 800 households in the province of Leyte: from Palo, Tanauan and Tacloban City. The surveys took place annually from 2015 to 2017. The resulting data provided information on aid received, recovery, community support, employment and livelihoods opportunities as well as insights into how different barangays are faring post-Yolanda.

A valuable picture has emerged of the challenges faced by different actors. Meanwhile connections have been identified between them, and further levels of influence within the recovery effort have been established. In November 2017, after presenting the research at international conferences, researchers shared the preliminary findings with a group of in-country stakeholders (including academics, civil society, aid agency representatives, and government officials). Recommendations were subsequently refined through feedback and comments.

The findings indicate that community rebuilding is more sustainable where communities are actively involved in schemes such as 'sweat equity', where beneficiaries donate their labour to the housing schemes that they will eventually occupy, and in the design and planning stages of their communities. However, the findings also revealed examples of lip service being paid to community involvement without it happening in a sustainable fashion. In order for sustainable rehabilitation to take place, more work needs to be done to engage the most vulnerable people within communities, such as women and own account (or selfemployed) workers.

Political sensibilities at the local level are important and rehabilitation work post-Yolanda is influenced by the pursuit of political survival at the local level, including at barangay level. In recognition of this context in November 2018, the University of the Philippines research team will lead a forum in Tacloban to present the research findings. Data from the household surveys for each barangay will be provided to local people who can see for themselves how each barangay is faring post-Yolanda. The team are also working with the university's Center for Integrative and Development Studies to produce discussion papers and policy briefs (online and print) which draw on the project, to be disseminated in time for the fifth anniversary of Typhoon Yolanda.

This research has contributed to an awareness of NGOs - including foreign aid agencies, and some national and local policymakers and government officials - of the need to further engage local communities in the rebuilding and rehabilitation of

\section{THE IMPACT}

their communities. There is recognition that listening to, and involving, communities at the design, planning and implementation stages of post-disaster recovery is likely to result in better outcomes and longer-term sustainability. Furthermore, the programme has contributed to capacity-building impact with junior faculty and senior students of the University of the Philippines Visayas - Tacloban College, who helped in data gathering, being mentored in field work research, and writing research reports.

According to Robert Dazo, Project Manager, Typhoon Haiyan Response, World Vision, the recommendations are set to influence future project programming:

\section{r}

The actionable steps were very helpful to us and the community where we provide our strategic interventions... the needs of the community are highlighted and can guide our project programming.

\section{FURTHER READING}

Atienza, M.E.; Eadie, P. and Tan-Mullins, M. (2017) Working Paper III - Building Back Better in the Aftermath of Typhoon Yolanda: Shelter and Resilience, www. projectyolanda.org/documents/working-paper-iii.pdf (accessed 7 June 2018)

Eadie, P. (2017) 'Typhoon Yolanda and the "Tyranny" of Resilience', Asia Dialogue: The Online Magazine of the University of Nottingham Asia Research Institute, 30 October, http://theasiadialogue.com/2017/10/30/ typhoon-yolanda-and-the-tyranny-of-resilience/ (accessed 22 June 2018)

Su, Y.; Mangada L. and Turalba, J. (2018) 'HappyWashing: How a "Happiness Campaign" Hurts Disaster Survivors', ReliefWeb, 27 April, https://reliefweb.int/ report/philippines/happy-washing-how-happinesscampaign-hurts-disaster-survivors (accessed 7 June 2018)

Tan-Mullins, M. et al. (2017) Four Years On: Rebuilding Disaster Affected Communities for a Sustainable Future: Policy Take-Away for Poverty Alleviation in the Wake of Typhoon Yolanda, www.projectyolanda.org/documents/ policy-recommendations.pdf (accessed 7 June 2018)

Project Alleviation in the Wake of Typhoon Yolanda (2018) www.projectyolanda.org (accessed 7 June 2018)

\section{THE IMPACT INITIATIVE}

\section{For International Development Research}

The Impact Initiative seeks to connect policymakers and practitioners with the world-class social science research supported by the ESRC-DFID Strategic Partnership, maximising the uptake and impact of research from: (i) the Joint Fund for Poverty Alleviation Research, and (ii) the Raising Learning Outcomes in Education Systems Programme. We seek to identify synergies between these programmes and their grant holders, support them to exploit influencing and engagement opportunities, and facilitate mutual learning. The Impact Initiative is a collaboration between the Institute of Development Studies (IDS) and the University of Cambridge's Research for Equitable Access and Learning (REAL) Centre.

All content is available under the Open Government License v3.0, except where otherwise stated.

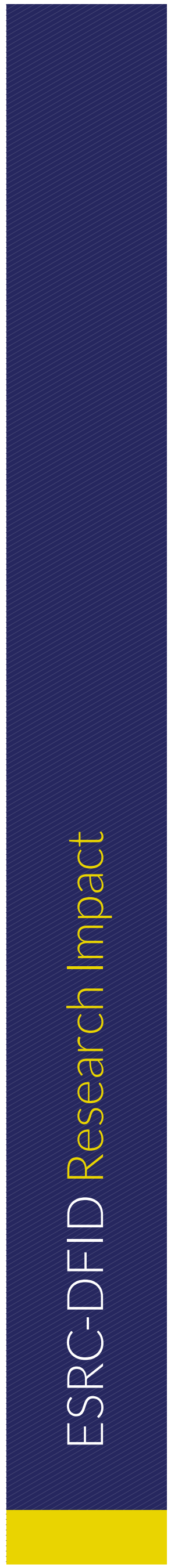

